\title{
Correction to: A Tale of Two Crises: Addressing Covid-19 Vaccine Hesitancy as Promoting Racial Justice
}

\section{Lauren Bunch ${ }^{1}$}

Published online: 6 March 2021

(c) Springer Nature B.V. 2021

\section{Correction to: HEC Forum https://doi.org/10.1007/s10730-021-09440-0}

In the original publication, the sentence "Most notable and famous are the Tuskegee syphilis experiments that occurred from 1932-1972, in which Black men in Macon County, AL were infected with syphilis under the guise of free health care (Jones 1993)." under the section "Drivers of Mistrust of Motives" was published incorrectly. The correct one is "Most notable and famous are the Tuskegee syphilis experiments that occurred from 1932-1972, in which Black men in Macon County, AL, many of whom had latent syphilis, were misled into believing that they would receive free health care in exchange for their participation (Jones 1993).

The original article has been corrected.

Publisher's Note Springer Nature remains neutral with regard to jurisdictional claims in published maps and institutional affiliations.

The original article can be found online at https://doi.org/10.1007/s10730-021-09440-0.

Lauren Bunch

bunch_lm@mercer.edu

1 Department of Community Medicine, Mercer University School of Medicine, 33 West 11th Street, Columbus, GA 31902, USA 